\title{
Current Approaches to Alkyl Levulinates via Efficient Valorization of Biomass Derivatives
}

\author{
Xiaofang Liu ${ }^{1}$, Wenjia Yang ${ }^{1}$, Qiuyun Zhang ${ }^{2}$, Can $\mathrm{Li}^{1 *}$ and Hongguo $\mathrm{Wu}^{1,3 *}$ \\ ${ }^{1}$ Guizhou Provincial Key Laboratory for Rare Animal and Economic Insects of the Mountainous Region, College of Biology \\ and Environmental Engineering, Guiyang University, Guiyang, China, ${ }^{2}$ School of Chemistry and Chemical Engineering, \\ Anshun University, Anshun, China, ${ }^{3}$ State-Local Joint Laboratory for Comprehensive Utilization of Biomass, Guizhou \\ University, Guiyang, China
}

OPEN ACCESS

Edited by:

Yaqiong Su, Eindhoven University of Technology, Netherlands

Reviewed by:

Jian He,

Jishou University, China Wenfeng Zhao,

Technical University of

Denmark, Denmark

Hu Pan,

Jiaxing University, China

${ }^{*}$ Correspondence:

Can L

lican790108@163.com

Hongguo Wu

whg0408@126.com

Specialty section:

This article was submitted to

Green and Sustainable Chemistry,

a section of the journal

Frontiers in Chemistry

Received: 31 May 2020

Accepted: 29 July 2020

Published: 15 October 2020

Citation:

Liu X, Yang W, Zhang Q, Li C and Wu H (2020) Current Approaches to

Alkyl Levulinates via Efficient Valorization of Biomass Derivatives.

Front. Chem. 8:794.

doi: 10.3389/fchem.2020.00794
Biomass is a potential non-food, carbon-neutral, and abundant resource, which can be used as an alternative to fossil fuels during the sustainable preparation of various platform chemicals. Alkyl levulinates (ALS) have found widespread application as flavorings, plasticizing agents, and fuel additives, as well as synthetic precursors to various building blocks. Several processes have been investigated to transform biomass and its derivatives into ALs, which mainly include: (i) direct esterification of levulinic acid ( $\llcorner A)$ with alkyl alcohols and (ii) alcoholysis reactions of renewable biomass feedstocks and their derivatives, including furfuryl alcohol (FAL), chloromethyl furfural (CMF), and saccharides. This review focuses on illustrating the effects of the biomass pretreatment step, catalyst texture, possible mechanisms, acidities, and intermediates on the synthesis of ALs from sustainable resources covering a wide range of intermediates, including diethyl ether (DEE), 4,5,5-triethoxypentan-2-one (TEP), ethoxymethylfuran (EMF), ethyl-D-fructofuranoside (EDFF), and ethyl-D-glucopyranoside (EDGP).

Keywords: alkyl levulinates, levulinic acid, furfuryl alcohol, chloromethyl furfural, acidic catalysts

\section{INTRODUCTION}

As the natural reserves of non-renewable resources such as petroleum, diesel, natural gases, and coal (fossil fuels) dwindle (Badgujar and Bhanage, 2015; Dhyani and Bhaskar, 2018) while causing unavoidable environmental issues, such as the emission of harmful gases and global-warming (Sun and Cheng, 2002; Wagh et al., 2016), extensive efforts must be devoted toward the search for alternative and renewable resources that are also environmentally friendly. Biomass is a carbon source used for renewable energy, which can provide multiple fuels, chemicals, and value-added platform molecules in a green and sustainable manner (Rackemann and Doherty, 2011; Tadele et al., 2017; Badgujar and Bhanage, 2018). Alkyl levulinates (ALs) derived from biomass have shown great potential for biorenewable fuels like bio-lubricants (Mukherjee et al., 2015), chemicals synthesis (Mullen et al., 2013), polymer or resin precursors (Alloaoua et al., 2014; Cousinet, 2014), green solvents (Lomba et al., 2011), plasticizers (Bloom, 2007), food-flavor agents (Yontz, 2011), and pharmaceuticals (Tsucha and Yoshida, 1994) during the effective utilization of biomass (Table 1). (Fiorentino et al., 2014). An investigation on Scopus indicated that the interest in developing ALs as a fuel has built up great momentum over the past 5 years. Research on ALs has mainly concentrated on methyl, ethyl, and butyl levulinate (Mascal and Nikitin, 2010b). Among these three levulinates, ethyl levulinate (EL) exhibits enhanced solubility with diesel (Christensen et al., 2011) 
TABLE 1 | Potential alkyl levulinates applications.

\begin{tabular}{|c|c|c|}
\hline Entry & Applications & Products \\
\hline 1 & Chemical industry & Chiral reagent, polyhydroxy alkanoates, lubricants, adsorbents, formic acid, valerates \\
\hline 2 & Fuels and fuel additives & EL, 2-methyltetraydrofuran, $\gamma$-valerolactone, angelica lactone, methyl levulinate, and other esters \\
\hline 3 & Pharmaceuticals & $\delta$-aminolevulinic acid, calcium levulinate, heterocylic derivatives of levulinic acid, angelica lactone, ketals, tetrapyrroles, succinic acid \\
\hline 4 & Food additives & $\gamma$-valerolactone, ethyl valerate, succinic acid, valerate esters \\
\hline 5 & Agricultural products & $\delta$-aminolevulinic acid, formic acid, lignins, ethyl formate \\
\hline 6 & Solvents and polymers & Diphenolic acid, succinic acid, pyridine, furans, epoxies, 1,4-butanediol, tetrahydrofuran, $N$-methyl-2-pyrrolidone, - $\gamma$-butyrolactone \\
\hline
\end{tabular}

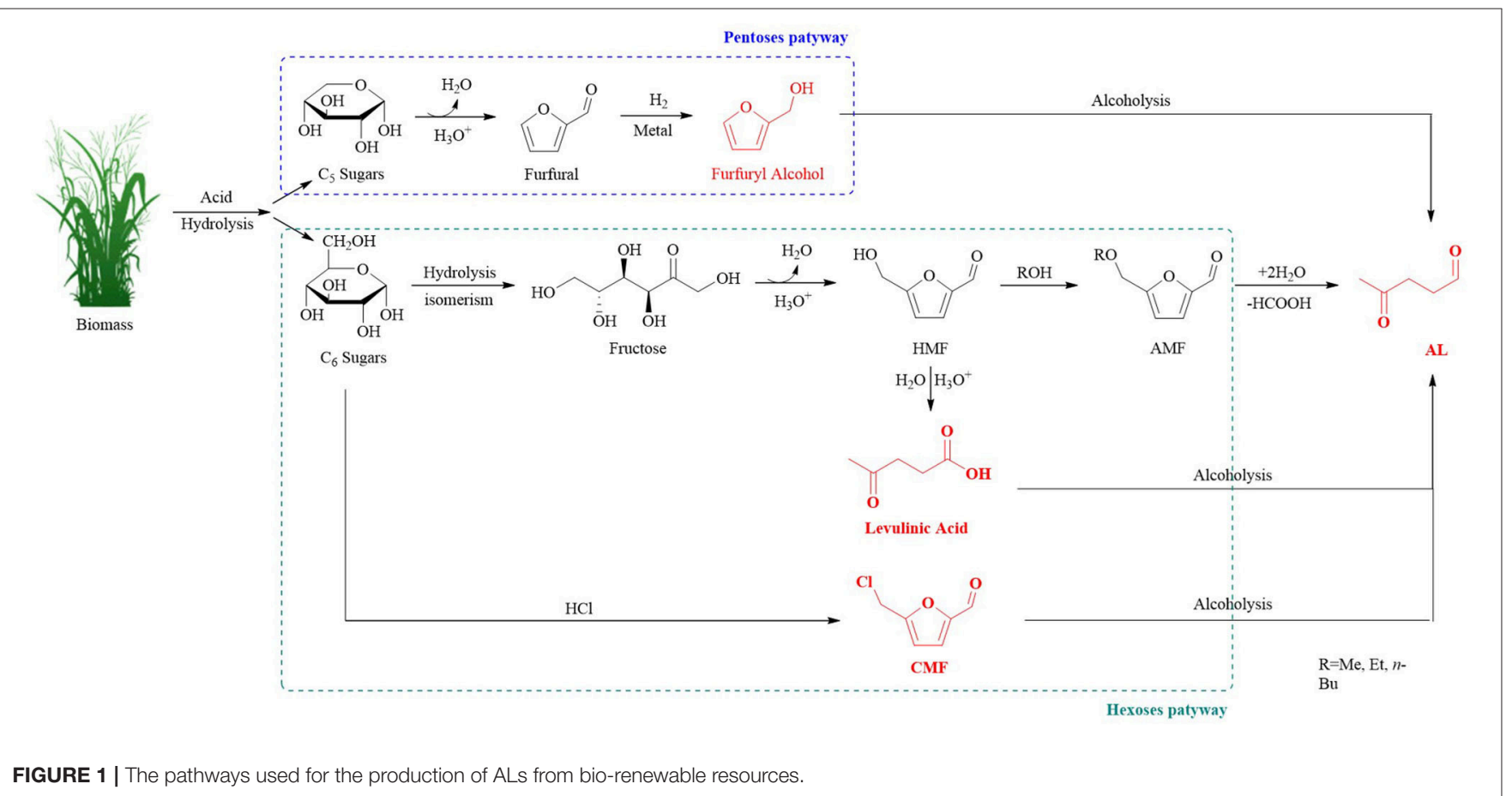

and only $\sim 4 \% \mathrm{NO}_{\mathrm{x}}$ emissions upon blending in diesel (Windom et al., 2011). Therefore, research has mostly been devoted toward the effective synthesis of EL.

ALs can be produced from biomass or via the conversion of levulinic acid (LA), furfuryl alcohol (FAL) (Démolis et al., 2014; Desidery et al., 2018), or chloromethyl furfural (CMF) (Mascal and Nikitin, 2010a). All of the possible reaction pathways involved in the alcoholysis procedure performed in the presence of acid catalysts have been reported (Figure 1). This review comprehensively contains all of the discussed approaches used for the production of ALs and executes critical evaluation of the various types of catalysts used in the conversion reactions: i) an overall understanding of the reaction parameters, texture and chemical properties, possible mechanism, and the reaction intermediates that favor the development to achieve high yields (Chia et al., 2013; Gupta et al., 2016), ii) different catalytic routes of ALs preparation, iii) utilization of various catalysts to obtain ALs, and iv) the future challenges and opportunities for the lab scale to the industry scale development of ALs.

\section{PREPARATION OF ALs}

Numerous advantages for using solid acid catalysts have been demonstrated including their low cost, ease of recycling from the product mixture, low equipment corrosion, and high thermal stability (Su et al., 2013b), while the application of heterogeneous materials toward the production of ALs requires further detailed discussion including the reaction temperature, time, substrates, acidic density and intensity, and textural properties.

\section{Routes to Prepare ALs From LA Heteropolyacid (HPA) as Catalysts}

The LA esterification reaction has been investigated using several solid acid catalysts toward the production of ALs in comparatively high yields (Pileidis and Titirici, 2016). Heteropolyacid (HPA) is a special species of acid composed of a combination of certain metals (tungsten, molybdenum, or vanadium) and p-block non-metals (silicon, phosphorus, or arsenic) with acidic hydrogen and oxygen atoms, which are 
generally applied as reusable acid catalysts for the preparation of fine chemicals (Yan et al., 2013; Wu et al., 2016a,b,c; Zhou et al., 2016; Manikandan and Cheralathan, 2017; Ramli et al., 2017a; Zheng et al., 2017; Luan et al., 2018; Vilanculo et al., 2018; Lucas et al., 2019). Numerous structural combinations can be prepared upon adjusting the metal and non-metal used. Furthermore, HPAs possess very strong Brønsted acidity and can be applied as homogenous or heterogeneous catalysts and solvents (Wu et al., 2016b; Zhou et al., 2016; Ramli et al., 2017a; Zheng et al., 2017).

HPAs have several disadvantages, including high solubility in water and other polar solvents, low specific surface area and thermal stability, and difficult reusability and regeneration (Gupta and Paul, 2014; Hu et al., 2015; Yamaguchi and Shirai, 2016), which hinders their application as efficient and effective catalysts for reactions with large molecules. A variety of diverse synthetic approaches have been studied to overcome these disadvantages including their immobilization on ordered silica, zirconia, and niobium (Narkhede et al., 2015).

HPA implanted into the Wells-Dawson (WD) structure provided EL with a $76 \%$ yield upon heating at $78^{\circ} \mathrm{C}$ for $10 \mathrm{~h}$ (Pasquale et al., 2012). Luan et al. carried out the production of ethyl, methyl, and isobutyl levulinates using an organic-salt of $\mathrm{H}_{4} \mathrm{SiW}_{12} \mathrm{O}_{40}$ as the catalyst (Luan et al., 2018). Manikandan and Cheralathan investigated heteropoly acid-supported silicalites in the synthesis of various ALs (Manikandan and Cheralathan, 2017).

Similarly, when changing WD to Keggin HPA $\left(\mathrm{H}_{3} \mathrm{PMo}_{12} \mathrm{O}_{40}\right)$, the EL yield increased to $93 \%$ under identical reaction conditions. The higher yield observed over Keggin HPA $\left(\mathrm{H}_{3} \mathrm{PMo}_{12} \mathrm{O}_{40}\right)$ was attributed to its higher acidity when compared to the WD structure. While transforming the alkylation substrates with isobutylene and methanol, WD HPA showed increased activity during the preparation of ALs when compared to Keggin HPAs, which was attributed to the higher adsorption of the reactants in the WD structure (Briand et al., 2003). Nevertheless, both WD- and Keggin-structured HPAs show comparable or higher activity than their corresponding homogeneous catalysts (Baronetti et al., 1998). However, leaching of the HPAs in polar solvents still occurs owing to the weak interactions formed between the HPAs and the support. The Keggin HPA $\left(\mathrm{H}_{4} \mathrm{SiW}_{12} \mathrm{O}_{40}\right)$ embedded in the channels of mesoporous $\mathrm{SiO}_{2}$ gave EL a $67 \%$ yield with improved recyclability when compared to the original HPA (Yan et al., 2013). Similarly, a combination of HPAs and zeolites was reported by Nandiwale et al. Improved stability was achieved using dodecatungstophosphoric acid (DTPA) supported on desilicated HZSM-5, which gave EL a $94 \%$ yield from LA at $76^{\circ} \mathrm{C}$ in $240 \mathrm{~min}$ (Nandiwale et al., 2013). High EL yields up to $77 \%$ were achieved over four reaction cycles demonstrating the high stability of the catalyst.

Neurock, Iglesia, and co-workers carried out a series of investigations on the acidity and reactivity of Keggin HPAs, which confirmed that the deprotonation energy (DPE) of the HPA was crucial for its activity (Macht et al., 2007, 2008). The HPA DPE determines the strong acidity of the material and thereby its increased reactivity in acid-catalyzed processes. The DPE of Keggin $\mathrm{H}_{4} \mathrm{SiW}_{12} \mathrm{O}_{40}$ was determined to be 1,105
$\mathrm{kJ} \cdot \mathrm{mol}^{-1}$, which was lower than Keggin $\mathrm{H}_{3} \mathrm{PMo}_{12} \mathrm{O}_{40}(1,126$ $\mathrm{kJ} \cdot \mathrm{mol}^{-1}$ ) (López et al., 2012). Hence, the two Keggin-structured HPAs prove the correlation between their activity and DPEs. To further enhance the acidity of Keggin HPAs, an acidic silicalike support such as $\mathrm{ZrO}_{2}$ was applied for the preparation of a variety of hybrid Keggin $\mathrm{HPA} / \mathrm{ZrO}_{2}$ composites containing both Brønsted and Lewis acid sites with increased activity toward the production of ALs when compared to HPA-silica (Su et al., 2013a). DRIFTS research on $\mathrm{H}_{3} \mathrm{PW}_{12} \mathrm{O}_{40} / \mathrm{ZrO}_{2}$ further verified the existence of Brønsted and Lewis acid sites, which was in accordance with this hypothesis (Alsalme et al., 2010; Wu et al., 2016a). In addition, the modification of Keggin HPAorganosilica/ $/ \mathrm{ZO}_{2}$ was proposed to prepare a hybrid catalyst, whereby a maximum AL yield of up to $95 \%$ was observed (Luan et al., 2018). Subsequently, several efforts have been devoted toward designing catalysts for the transformation of LA into ALs with enhanced stability, available active sites, and recyclability.

\section{Zeolites as Catalysts}

Other factors in regard to the catalyst that influence the reactivity and selectivity during the conversion of LA into EL are its texture, porosity, specific surface area, and availability of active sites. Well-organized materials, such as zeolites, contain functionalities that can be used to control the acidity and pore size to achieve better EL yields. For example, desilicated H-ZSM-5 (DHZDM-5) has moderate acidity $\left(0.73 \mathrm{mmol} \cdot \mathrm{g}^{-1}\right)$, a high surface area $\left(427.6 \mathrm{~m}^{2} \cdot \mathrm{g}^{-1}\right)$, and mesoporosity, which affords EL a $95 \%$ yield under autogenous pressure (Nandiwale et al., 2014). The obtained EL yield was comparable to that obtained over HPA/H-ZSM-5 at high temperature $\left(130^{\circ} \mathrm{C}\right)$. To account for this phenomena, Janik et al. carried out DFT calculations on the mobility of the isolated protons. The results indicate the relatively low activation barrier of phosphotungstic acid $(\mathrm{Ea}=$ $103.3 \mathrm{~kJ} \cdot \mathrm{mol}^{-1}$ ) (Janik et al., 2005), which was also calculated by Ryder et al. for H-ZSM-5 $\left(\mathrm{Ea}=117.2 \mathrm{~kJ} \cdot \mathrm{mol}^{-1}\right.$ ) (Ryder et al., 2000). The activation barrier was confirmed to be significantly reduced $\left(\mathrm{Ea}=11.2 \mathrm{~kJ} \cdot \mathrm{mol}^{-1}\right)$ in the presence of hydrated protons in the Keggin HPA structures (Janik et al., 2005). The acid strength was directly proportional to the protons mobility and thus, a slightly higher reaction temperature was required for the conversion of LA into EL using desilicated H-ZSM5 (Nandiwale et al., 2014). Dharane and Bokade reported the production of butyl levulinate using dodecatungsten phosphoric acid inserted in acid-treated clay (K-10) (Dharne and Bokade, 2011). Therefore, the lower proton mobility and pore structure of zeolites lead to the higher selectivity observed toward EL during the esterification of LA, which was attributed to the highly efficient mass transfer observed within the moderate pore channels in zeolites (Yan et al., 2013). Patil et al. further demonstrated that mesoporous zeolites (micro/meso-HZ-5) with larger cavities enhanced the substrates access to the acidic sites (total acidity $=0.73 \mathrm{mmol} \cdot \mathrm{g}^{-1}$ ) and gave a high EL yield of up to $95 \%$ when compared with a traditional microporous zeolite $\left(\mathrm{H}-\mathrm{BEA}_{0.10}\right.$; total acidity $=0.69 \mathrm{mmol} \cdot \mathrm{g}^{-1}, \mathrm{EL}$ yield $\left.=39.2 \%\right)$ (Patil et al., 2014). The achievement was confirmed further by Nandiwale et al. on the esterification of LA with $n$-butanol 


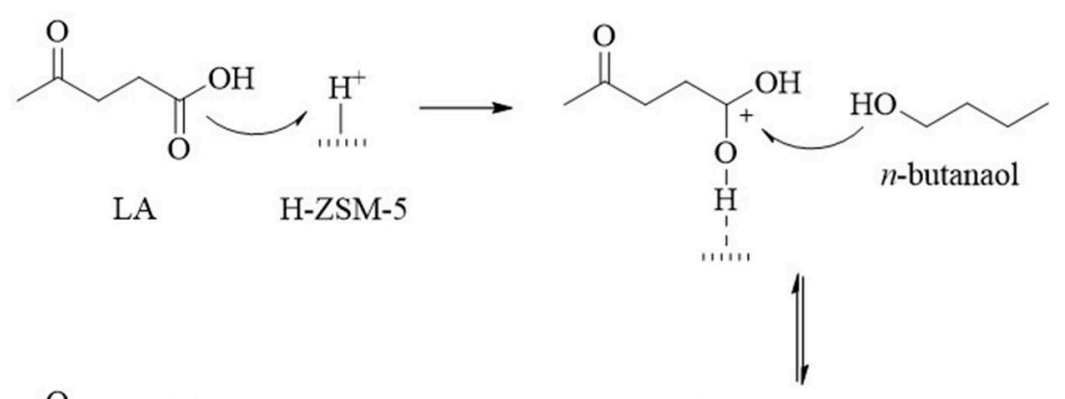<smiles>CCCCOC([18OH])([18OH])CCC(C)=O</smiles><smiles>CCCC[OH+]C(O)(CCC(C)=O)O[TlH]</smiles><smiles>CCCCO[C@@H](CCC(C)=O)O[InH]</smiles><smiles>CCCCOC(=O)CCC(C)=O</smiles>

$\mathrm{BL}$

(Nandiwale and Bokade, 2015), and the proposed mechanism is shown in Figure 2.

\section{Metal Oxides as Catalysts}

Mesoporous metal oxides are potential alternatives to zeolites as catalytic supports (Dave and Pant, 2011; Mondal et al., 2015). During the esterification for LA to prepare ALs, acidic catalysts are desirable. For instance, sulfated zirconia $\left(\mathrm{SO}^{2-} / \mathrm{ZrO}_{2}\right)$ exerts a higher Hammett acid strength $\left(H_{0}=-16.04\right)$ than homogeneous pure sulfuric acid $\left(H_{0}=-11.99\right)$, which indicates it is a superacid (Yadav and Nair, 1999). Owing to their high acidity, solid superacids embedded into various metal oxides have been developed toward the transformation of LA into ALs. Sulfated tin oxide gave EL a $44 \%$ yield, which was significantly better than that observed using non-sulfated tin oxide $(6 \%$ EL yield) under identical reaction conditions (Fernandes et al., 2012). For the resulting sulfated oxides, the acidity followed the order of $\mathrm{SO}_{4}^{2-} / \mathrm{ZrO}_{2}>\mathrm{SO}_{4}^{2-} / \mathrm{Nb}_{2} \mathrm{O}_{5}>\mathrm{SO}_{4}^{2-} / \mathrm{TiO}_{2}>$ $\mathrm{SO}_{4}^{2-} / \mathrm{SnO}_{2}$. (Rao et al., 2006), while the EL yield trend observed with the sulfated metal oxides followed the order of $\mathrm{SO}_{4}^{2-} / \mathrm{SnO}_{2}$ $>\mathrm{SO}_{4}^{2-} / \mathrm{TiO}_{2}>\mathrm{SO}_{4}^{2-} / \mathrm{ZrO}_{2}>\mathrm{SO}_{4}^{2-} / \mathrm{Nb}_{2} \mathrm{O}_{5}$ (Yadav and Nair, 1999). The acidic strength was opposite to the EL yield and could be attributed to the texture, specific surface area, and pore size of the catalyst, which in turn determines the accessibility of the active sites. Fernandes et al. carried out these investigations and the results suggested that the poor activity (14\% EL yield) observed for the $\mathrm{SO}_{4}^{2-} / \mathrm{Nb}_{2} \mathrm{O}_{5}$ catalyst can be attributed to its lower $\mathrm{S}_{\mathrm{BET}}\left(67 \mathrm{~m}^{2} \cdot \mathrm{g}^{-1}\right)$ when compared to $\mathrm{SO}_{4}^{2-} / \mathrm{TiO}_{2}$ $\left(107 \mathrm{~m}^{2} \cdot \mathrm{g}^{-1}\right)$ and $\mathrm{SO}_{4}^{2-} / \mathrm{SnO}_{2}\left(130 \mathrm{~m}^{2} \cdot \mathrm{g}^{-1}\right)$ (Fernandes et al., 2012). Similarly, the low $\mathrm{S}_{\mathrm{BET}}\left(51.7 \mathrm{~m}^{2} \cdot \mathrm{g}^{-1}\right)$ of sulfated zirconia $\left(\mathrm{SO}_{4}^{2-} / \mathrm{ZrO}_{2}\right)$ displays an EL yield of $27.5 \%$ at $70^{\circ} \mathrm{C}$, which was significantly increased up to $80 \%$ when using mingling mesoporous silica $\left(\mathrm{S}_{\mathrm{BET}}=130 \mathrm{~m}^{2} \cdot \mathrm{g}^{-1}\right)$ synthesized via a successive co-precipitation-impregnation method. Optimization studies confirmed that $\mathrm{ZrO}_{2}$ with a Si content of $5.0-10 \mathrm{~mol} \%$ $\mathrm{Si}$ per $\mathrm{Zr}$ exhibits the best catalytic performance (Kuwahara et al., 2014). However, when catalyzed using sulfated metal oxides such as $\mathrm{SO}_{4}^{2-} / \mathrm{ZrO}_{2}, \mathrm{SO}_{4}^{2-} / \mathrm{SnO}_{2}$, and $\mathrm{SO}_{4}^{2-} / \mathrm{Nb}_{2} \mathrm{O}_{5}$ at elevated temperature $\left(160^{\circ} \mathrm{C}\right)$, each catalyst showed improved EL yields ( $70 \%$ ), which was attributed to their enhanced activity (Yadav and Yadav, 2014). In addition, the higher density and availability of the active acid sites in the catalyst may enhance the EL yield (Li Z. et al., 2014). Dispersing $\mathrm{TiO}_{2}$ onto sulfated zirconia nanoparticles increases the sulfur complex density up to 1.71 sulfate groups per $\mathrm{nm}^{3}$ and when distributed on the surface of a $\mathrm{ZrO}_{2} / \mathrm{TiO}_{2}$ support results in a significant improvement when compared to their corresponding $\mathrm{TiO}_{2}$ nanocomposites (0.35 sulfate groups per $\mathrm{nm}^{3}$ ) (Li et al., 2012). Based on the above discussion, Kuwahara and co-workers reported a high EL yield of up to $80 \%$ from LA upon heating at $70^{\circ} \mathrm{C}$ over 1,440 min using sulfated $\mathrm{Zr}$-SBA-15, which was attributed to the appropriate acid site density of sulfated $\mathrm{ZrO}_{2}$ immobilized on the ordered and mesoporous silica template (Kuwahara et al., 2013). Therefore, the acid site density, acid strength, and predominant 
morphological characteristics contribute to the higher EL yield. However, the drawback of deactivation via hydration of the sulfur complexes in sulfated metal oxide catalysts occurs in an aqueous phase or when water is produced as a product of the reaction, which impedes the development of numerous reactions.

\section{Sulfonic Acid-Functionalized Materials as Catalysts}

To overcome the limitations of sulfated metal oxides, sulfonic acid-based materials have been introduced as an alternative to performing the desired reactions. Sulfonic acid ions construct a hydrophobic microenvironment in the reaction medium, which protects the catalyst from water molecules generated during the reaction, thus guaranteeing their stability (Song et al., 2015). Therefore, sulfonic acid functionalized mesoporous materials have several advantages including high surface area, accessible active sites, appropriate pore structures, and high stability for achieving the desired ALs in good yield.

Silica has aroused great interest from researchers owing to its superior features, such as ordered porosity, low cost, adjustable surface functionalities, high surface area, and chemical and thermal stability (Melero et al., 2013; Maggi et al., 2016; Chermahini and Nazeri, 2017; Enumula et al., 2017; Ramli et al., 2018; Yang and Tang, 2019).

EL was obtained in $100 \%$ yield upon heating at $117^{\circ} \mathrm{C}$ for $2 \mathrm{~h}$ using propylsulfonic acid-functionalized mesoporous silica (Pr-SO $\left.{ }_{3} \mathrm{H}-\mathrm{SBA}-15\right)$, which could be reused three times without needing to be regenerated (Melero et al., 2013). Similarly, Ramli et al. prepared methyl levulinate in 69\% yield over sulfated silica under mild reaction conditions (Ramli et al., 2018). Meanwhile, Chermahini and Nazeri reported the use of aluminum-containing MCM-41 for the production of isobutyl and butyl levulinate, and verified that the regenerated catalyst can be recycled without any obvious loss of activity (Chermahini and Nazeri, 2017). Besides, the insertion of tungsten oxide into SBA16 also showed enhanced acidity and catalytic performance, and gave a higher yield of the desired levulinate products. This was attributed to the uniform distribution of acidic tungsten oxide sites over the large specific surface area and ordered structure of SBA-16 (Enumula et al., 2017). These materials combined with silica-based materials are easily deactivated in polar solvents because of the H-bonding formed between the active silicafunctionalized groups and polar solvent molecules.

Inspired by these outstanding results, Oliveira et al. conducted studies using carbon nanotubes (CNT) as a support with a high surface area available for sulfonation. By varying the functionalization temperature and number of acid sites, the activity of the sulfonated CNT catalyst can be easily adjusted and controlled by its acid site density. Unfortunately, the overall EL yield was relatively low $(\sim 50 \%)$ because of the selectivity and strong chemisorption of LA on the CNT surface (Oliveira and Teixeira Da Silva, 2014).

An innovative approach to prepare bifunctional acid-base catalysts using $\mathrm{Zr}$-containing metal-organic frameworks (MOFs) formed using 2-aminoterephthalate ligands has been proposed by Corma and coworkers (Cirujano et al., 2015). The interactions formed between the catalyst, LA, and alcohol were activated on the catalytic centers of the metal $(\mathrm{Zr})$ and amino group in the ligand. The results demonstrate that these centers play different roles within proximity to one another and they all allowed the simultaneous activation processes to occur. The resulting $\mathrm{NH}_{2}$ Zr-MOF catalysts afford a high EL yield (>95\%) under relatively mild reaction conditions $\left(78^{\circ} \mathrm{C}\right)$. The excellent performance was further confirmed by the turnover frequency (TOF), which was measured to be $230 \mathrm{~h}^{-1}$, which was $>2$-fold higher than that obtained using homogeneous $p$-toluene sulfonic acid (TOF $=$ $\left.120 \mathrm{~h}^{-1}\right)$.

Several research groups have explored the effectiveness of various heterogeneous catalysts toward the production of EL from LA under optimal reaction conditions. Sulfonated carbon nanotubes have also been explored as a catalyst for the synthesis of ALs (Oliveira and Teixeira Da Silva, 2014). However, this type of catalyst is not recyclable when employed in the LA esterification reaction and exhibits a lower catalytic performance than that observed using the classic benchmark catalyst (Amberlyst-15).

Resins are organo-polymeric materials, which possess high surface areas, high ion-exchange capacities, and various functionalities depending on the type of resin used (Tejero et al., 2016; Marrocchi and Vaccaro, 2017; Ramli et al., 2017b; Kokare et al., 2018; Trombettoni et al., 2018). The main catalytic resins are Amberlyst-15, Amberlyst-16, Amberlyst-36, Amberlyst-70, Purolite, Dowex, and polystyrene-supported $p$-toluensulfonic acid. The existence of sulfonic-acid groups $\left(-\mathrm{SO}_{3} \mathrm{H}\right)$ endows the resin catalysts with acidic properties, which initiate the conversion process (Tejero et al., 2016; Ramli et al., 2017b; Kokare et al., 2018). Ramli et al. developed an ion-exchange resin (Amberlyst-15) for use as a solid acid catalyst in the production of ALs under safe media flow conditions, confirming that the process was chemically and environmentally efficient (Ramli et al., 2017b). Kokare et al. carried out response surface optimization for the preparation of $n$-butyl levulinate over Amberlyst-15 and a maximum LA conversion of $97 \%$ was achieved using a LA to $n$-butanol molar ratio of $1: 4$ at $124^{\circ} \mathrm{C}$ (Kokare et al., 2018). Meanwhile, a low divinylbenzene (DVB) content gel-type resin (Dowex 50Wx2; 2\% DVB) gave good yields of the desired AL products, which was attributed to the accessibility of the reactants to the acid centers in the highly swollen and low polymer density resin (Tejero et al., 2016). The reusability of Amberlyst-15 and Amberlyst-70 is highly practical and requires a simple washing step, and are therefore less expensive when compared to other resin-based catalysts. However, the instability of Amberlyst-15 at high temperatures greatly impedes its further application. The major challenges for the employment of resins in these catalytic conversion reactions are their high cost, thermal instability, non-flexibility, H-bond formation, and destabilization of the active centers.

\section{Routes to Prepare ALs From Biomass Feedstocks and Their Derivatives \\ FAL as a Feedstock}

Zhang et al. have explored a wide variety of acid catalysts including zeolite, ion-exchange resins, ionic liquids (ILs), and HPA toward the synthesis of butyl levulinate (BL) (Zhang 
et al., 2011). The results showed that the production of 2-butoxymethylfuran (BMF) was faster than the subsequent conversion reaction to form $\mathrm{BL}$. In addition, reports have speculated that BMF reacts with water, which accelerates the reaction. When one equivalent of water was added to the reaction, BL was obtained in 93\% from FAL. This confirmed the higher activity observed in the presence of water when compared to the reaction performed in the absence of water (BL yield $=88 \%$ ). Based on their experimental results, a proposed mechanism for the conversion of FAL into ALs indicated that the reaction may occur via the formation of an alkoxymethylfuran intermediate.

Similar conclusions have been reported by Huang et al. when studying the conversion of FAL into methyl levulinate (ML) (Huang et al., 2016). The results indicated multiple routes involving the production of methoxymethylfuran (MMF) and 4,5,5-trimethoxypentan-2-one (TMP) as intermediates occurred during the reaction. Their investigations demonstrated that TMP was formed from MMF under specific reaction conditions, which indicates that both TMP and MMF promote the synthesis of ML. When the reaction system was carried out using FAL and ethanol to prepare EL, the observation of the above-mentioned intermediates proposed in the mechanism was difficult. However, the published studies established two clear observations. The formation of the reaction intermediates (TEP and/or EMF) was slower than the reaction converting FAL into multiple intermediates. In addition, the yield of DEE formed in the reaction when compared to EL or the reaction intermediates (TEP and EMF) was low and various pathways contributed to the formation of EL.

The production of DEE during the synthesis of EL depends on the texture of the catalyst used, including the pore structure and accessibility of the active sites for ethanol dehydration derived from the ethanolysis of FAL. The results revealed the acid catalysts used for the FAL-EL procedure, reaction temperature, time, acidic sites employed, and observed EL yields. Owing to the microporous and non-swelling structure of gel-type resins (Dowex, Amberlyst, etc.), a higher amount of DEE was formed and a lower EL yield $(<60 \%)$ was obtained, which can be ascribed to the improved accessibility of the active sites to ethanol when compared to FAL (Lange et al., 2009). This was different from resin catalysts with mesoporous structures (carbon-based, silica-based, etc.), which showed better EL yields (>80\%) and lower amounts of DEE depending on the superior accessibility of the acidic sites to FAL when compared to ethanol (Lange et al., 2009; González Maldonado et al., 2012). Sulfonic acid-functionalized mesoporous materials (activated carbon, silica-carbon composites, organosilica hollow nanospheres, and sulfated MOF) have been used in the production of EL utilizing the ethanolysis procedure giving EL yields in the range of 8090\% (Russo et al., 2014a,b; Zhu et al., 2014; Liu et al., 2016; Guo et al., 2020). In addition, the density of the acidic groups has been shown to affect the reaction rate. For example, adjusting the $-\mathrm{SO}_{3} \mathrm{H}$ density from 5.4 to $17 \%$ in propylsulfonic acidfunctionalized ethane bridged organosilica hollow nanospheres (Pr-SO ${ }_{3} \mathrm{H}$-Et-HNS) gave EL yields ranging from 52.5 to $72 \%$ under the same reaction conditions. Meanwhile, with the catalyst MIL-101(Cr)-SO ${ }_{3} \mathrm{H}$, EL yield was enhanced up to $79.1 \%$ when FAL was used as the starting material ascribed to the MOF texture $\left(\mathrm{S}_{\mathrm{BET}}=1,492 \mathrm{~m}^{2} \cdot \mathrm{g}^{-1}\right.$, titration $\left.\left[\mathrm{mmol}(\mathrm{H}+) \cdot \mathrm{g}^{-1}\right]=1.01\right)$ (Figure 3).

Sulfonic acid-functionalized ILs, which have similar nonswelling properties, have also been explored by Wang et al. to obtain better EL yields (Wang et al., 2014). A comparison of sulfonic acid and non-sulfonic acid-functionalized IL catalysts bearing $\mathrm{HSO}_{4}^{-}$anions was carried out. Using 3-butyl-1-methyl$1 \mathrm{H}$-imidazole-3-ium [BMIm] as the cation gave a low EL yield $(\sim 34 \%)$ at $120^{\circ} \mathrm{C}$, while replacing [BMIm] with BMIm-SH

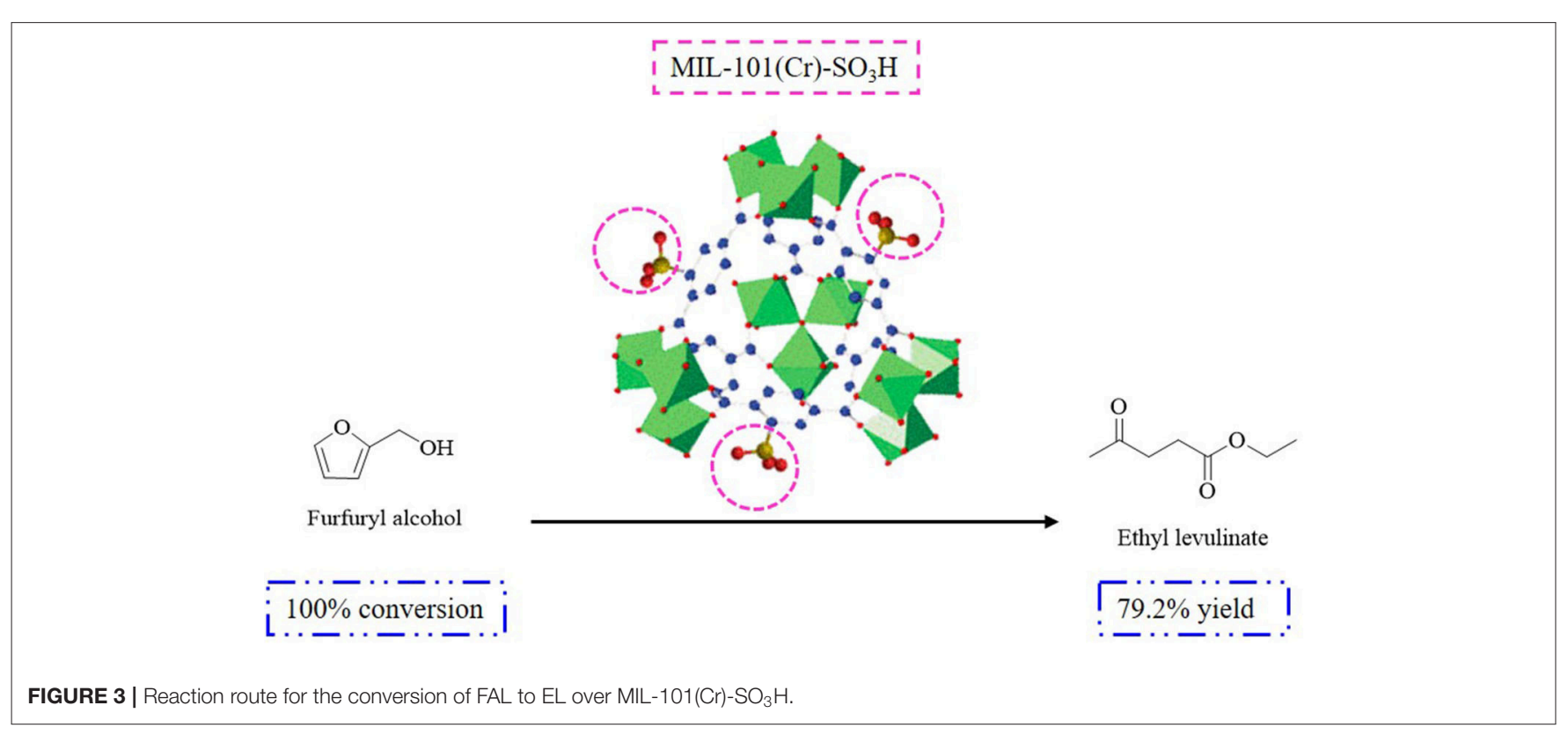


produces a significantly greater yield of EL (92\%) under the same reaction conditions (Wang et al., 2014). The higher yield of EL obtained using the sulfonic acid functionalized IL was ascribed to the higher acid intensity. The acid intensities of BMIm-SH and BMIm IL were 1.2 and 2.5, respectively when measured using the Hammett acidity, which was comparable to conventional acids (i.e., $\mathrm{H}_{2} \mathrm{SO}_{4}$ ) (Liu et al., 2008). Subsequently, the results indicated that the cationic sulfonic group facilitates proton transfer and the protonation of FAL, which then enhances the yield of the target product (Li et al., 2015a,b). Similar tendencies were verified by Hengne et al. who showed that the EL yield obtained over a non-sulfonic IL (1- methyl imidazolium [MIm]) was lower (65\%) than that obtained using a sulfonic acid-functionalized IL (95\%) (Hengne et al., 2013).

Possessing both Brønsted and Lewis acidity, metal salts have been investigated in the acid-catalyzed transformation of biomass-derived oxygenates (Loerbroks et al., 2014). During the reaction, the Lewis acid active site coordinates with the oxygen atom in FAL, which was verified by the stability of the as-formed complex and further decreased the activation barrier (Pidko et al., 2010). To confirm the effect of the Lewis acidity, Peng et al. researched various aluminum salts $\left(\mathrm{AlCl}_{3}, \mathrm{Al}_{2}\left(\mathrm{SO}_{4}\right)_{3}, \mathrm{Al}\left(\mathrm{NO}_{3}\right)_{3}\right.$, and $\left.\mathrm{Al}\left(\mathrm{C}_{6} \mathrm{H}_{5} \mathrm{SO}_{3}\right)_{3}\right)$ as catalysts for the FAL-EL conversion reaction. A maximum EL yield of $74 \%$ was obtained using $\mathrm{AlCl}_{3}$ as a catalyst at $110^{\circ} \mathrm{C}$ for $3 \mathrm{~h}$. This was attributed to the weaker Brønsted acidity of $\mathrm{AlCl}_{3}(\mathrm{pH}=0.89)$ compared to $\mathrm{Al}(\mathrm{OTf})_{3}$, which shows greater Brønsted acidity $(\mathrm{pH}=0.12)$ (Peng et al., 2015). The EL yield obtained using $\mathrm{AlCl}_{3}$ was maintained over six successive runs of the reaction, demonstrating its high stability, which fulfills the requirements of its future commercialization (Peng et al., 2015). For comparison, Khusnutdinov et al. obtained a higher EL yield (95\%) under milder reaction conditions $\left(70^{\circ} \mathrm{C}\right)$ using iron(III) acetylacetone (Khusnutdinov et al., 2007).

Heterogeneous acidic catalysts, such as zeolites, have been recently studied for the ethanolysis of FAL used to produce EL. An excellent catalytic performance has been demonstrated using hierarchical HZ-5 and HZSM-5, which give EL yields up to 73.0 and $85.8 \%$, respectively at $100-120^{\circ} \mathrm{C}$ (Zhu et al., 2014; Nandiwale et al., 2015). Nandiwale et al. were interested in the preparation of zeolite materials upon adjusting the $\mathrm{Si} / \mathrm{Al}$ ratio (SAR) and further explored the effect of their Brønsted acidity on the EL yield (Nandiwale et al., 2015). A significant achievement was reported using the zeolite prepared with a SAR of 30.15 exhibiting the strongest Brønsted acidity $(\sim 0.73$ $\left.\mathrm{mmol} \cdot \mathrm{g}^{-1}\right)$, which gave the maximum EL yield when compared to the other zeolites studied. Based on the published findings, the overall yield of EL obtained over the zeolite catalysts was affected by the formation of DEE, which leads to a serious loss of ethanol. These limitations can be overcome by modifying the textural properties of the zeolite materials. Antunes et al. have prepared and perfected a series of zeolite catalysts by introducing three different procedures to change the textural properties of the catalyst (Antunes et al., 2015, 2016). By introducing an organic template, Al-TUD-1 generated a smaller pore size distribution to increase the accessibility of the acidic sites to FAL, which produced a higher EL yield. Beta/TuD-1 was prepared with a reduced crystallite size and ITQ-2 was synthesized via the delamination of MCM-22 (Lima et al., 2010a,b; Antunes et al., 2012; Neves et al., 2013). Among the three catalysts studied, AlTUD-1 exhibited a SAR of 21 and an acidity density of 197 $\mu \mathrm{mol} \cdot \mathrm{g}^{-1}$ and provided a significant yield of EL ( $80 \%$ over $24 \mathrm{~h}$ with negligible DEE formed) at $140^{\circ} \mathrm{C}$ (Neves et al., 2013). The delamination of MCM-22 was similar to Al-TUD-1, which opened the pore structure to provide increased accessibility to FAL (Corma et al., 1998). The surface area and the total acidity of the ITQ-2 catalyst were enhanced two- and 1.5-fold, respectively when compared to MCM-22. The results were in accordance with those reported by Katz et al. using layered zeolite and the delamination procedure was shown to be responsible for the enhancement in the acidity and surface area (Ogino et al., 2013). As a consequence, a significant enhancement in the EL yield (60\%) was obtained using ITQ-2 when compared to MCM-22 (47\%) at $140^{\circ} \mathrm{C}$ over $24 \mathrm{~h}$ (Neves et al., 2013).

Based on the above analysis, modified mesoporous aluminosilicates materials with high surface areas and appropriate pore sizes guaranteed the accessibility of the active sites for the reactants, which significantly improves the yield of EL. However, the production of undesired by-products containing aromatic compounds, cyclic hydrocarbons, and lactic acid poly-condensation compounds need to be inhibited to enhance the yield of EL (Dusselier et al., 2015).

Zhu et al. have also studied functionalized graphene oxide (GO) as an acid catalyst for the conversion of FAL into EL. The results showed that lamellar-structured nano-GO is beneficial for the accessibility of the reactants. Under the optimal reaction conditions $\left(120^{\circ} \mathrm{C}\right)$, a high $\mathrm{EL}$ yield of up to $95.5 \%$ was obtained when compared to the other catalysts studied (modified zeolites, HPAs, and sulfonic acid functionalized catalysts; Zhu et al., 2014). The strong hydrogen bonding interactions formed by the synergistic effect observed between the various acid sites including sulfonic acid groups and carboxyl/hydroxyl functionalities are responsible for the excellent performance of the GO catalyst. The carboxyl/hydroxyl groups in GO have a strong affinity toward the hydroxyl group in FAL, which provides unprecedented adsorption and favors the accessibility of the active acid sites for the reactants (Zhu et al., 2015). In regard to the Brønsted acidity, the sulfonic acid density of GO is lower than $\mathrm{H}_{2} \mathrm{SO}_{4}$ and $p$-TSA, however, the higher yield of EL obtained using GO can be attributed to the crucial role played by this synergistic effect.

In addition to the catalytic performance, the recyclability of the catalyst is also a significant factor for its industrial applications. For instance, DH-ZSM-5 is reusable over five continuous runs without any significant loss in its activity. After the sixth run, the conversion of FAL decreased from 95 to 93\%, demonstrating that the recycling of DH-ZSM-5 was feasible (Nandiwale et al., 2014). On the contrary, the sulfonated carbon catalyst $\left(\mathrm{AC}-\mathrm{Fe}-\mathrm{SO}_{3} \mathrm{H}\right)$ reported by Zhang and Chen, for which the yield of EL decreased from 58 to $46 \%$ after three runs, showed insufficient stability for industrial application (Zhang and Chen, 2016). Similarly, the EL yield decreased from 45 to $36 \%$ over six runs using USY zeolite (Chang et al., 2015). Further exploration is needed to achieve stable, convenient, and excellent catalytic performance during the conversion of FAL into EL. 


\section{CMF as a Feedstock}

Besides the existing substrates, researchers have devoted great efforts toward developing the synthesis of EL from low-cost and novel starting materials, such as CMF (Li H. et al., 2014). For example, Breeden et al. have developed the synthesis of CMF (>70\% yield) from HMF, glucose, and inulin at $80^{\circ} \mathrm{C}$ over 15 min (Breeden et al., 2013). Mascal et al. successfully obtained high EL yields up to $84.7 \%$ from CMF at $160^{\circ} \mathrm{C}$ over $30 \mathrm{~min}$ (Mascal and Nikitin, 2010a). The investigators confirmed the feasibility of a one-pot process to produce EL directly from biomass, even seed oil, using CMF as an intermediate (Mascal and Nikitin, 2010a). At room temperature, the obtained CMF intermediate remained stable in high yield (Mascal and Nikitin, $2010 \mathrm{a})$, while at elevated temperature $\left(>100^{\circ} \mathrm{C}\right)$, the ethanolysis reaction proceeds to convert the $\mathrm{CMF}$ intermediate into $\mathrm{EL}$ via TEP during the FAL ethanolysis process.

\section{Saccharides as a Feedstock}

With respect to the starting material, EL can be directly prepared from saccharides, such as carbohydrates, sucrose, glucose, or fructose via a one-pot process using an acid catalyst and alcohol as the reaction media. The one-pot process generates multiple by-products, which result in a low EL yield (Liu et al., 2011; Peng et al., 2011). Fructose has been reported to display excellent activity over multiple acid catalysts when compared to other monosaccharides (glucose and mannose).

Similar to the FAL conversion reaction, sulfonic acid functionalized ILs bearing $\left[\mathrm{BMIm}-\mathrm{SO}_{3} \mathrm{H}\right]$ and $\left[\mathrm{NE}_{\mathrm{t} 3} \mathrm{~B}-\mathrm{SO}_{3} \mathrm{H}\right]$ cations have been developed to generate a comparable yield of EL ranging from 67 to $77 \%$ starting from fructose (Saravanamurugan et al., 2011). The difference observed in the EL yield was attributed to the acid intensity of the anions $\left([\mathrm{OMS}]^{-},\left[\mathrm{HSO}_{4}\right]^{-}\right.$, and $\left.\left[\mathrm{NTf}_{3}\right]^{-}\right)$. Owing to the uniform structure of SBA-15 bearing sulfonic acid functionalities, its high Brønsted acid density $\left(731 \mu \mathrm{mol} \cdot \mathrm{g}^{-1}\right)$ and surface area (819 $\mathrm{m}^{2} \cdot \mathrm{g}^{-1}$ ) provide EL in $70 \%$ yield under the optimum reaction conditions $\left(140^{\circ} \mathrm{C}\right.$ over $\left.24 \mathrm{~h}\right)$ (Saravanamurugan and Riisager, 2012). Similarly, Liu et al. have introduced a sulfonic acid functionalized Amberlyst-15 catalyst for the preparation of EL in $\sim 73 \%$ yield (Liu et al., 2013). To explore the effect of the acid density on the formation of EL, a series of sulfonated mesoporous carbon catalysts were synthesized with decreasing acid site density $\left(5.67,4.26,2.89\right.$, and $\left.1.75 \mathrm{mmol} \cdot \mathrm{g}^{-1}\right)$. A declining trend in the EL yield $(84,69,60$, and $45 \%)$ was observed in the presence of the sulfonated mesoporous carbon structures (Liu et al., 2013).

The observed results indicate that the EL yield increases upon increasing the reaction time and temperature. For instance, the EL yield was improved to $37 \%$ when the reaction was conducted at a higher temperature $\left(140^{\circ} \mathrm{C}\right)$ when compared to $130^{\circ} \mathrm{C}$ in the study reported by Zhu and coworkers (Wang et al., 2013). Furthermore, the utilization of a metal promoter on HPA can also afford a better EL yield. The results achieved by Zhao et al. showed that doping HPA with monovalent potassium cations $\left(\mathrm{K}^{+}\right)$leads to an increase in the acidity and higher EL yield (64.6\%), which was further improved to $68.7 \%$ because of the use of toluene and heating at $150^{\circ} \mathrm{C}$ (Zhao et al., 2015).
Li et al. developed a fructose-EL conversion reaction catalyzed by $\mathrm{HY}$ zeolites with a SAR of 2.6 at $230^{\circ} \mathrm{C}$, which achieved a $52 \%$ yield of EL (Li et al., 2016). The results were in contrast with the better EL yield ( $>80 \%$ ) obtained at a lower temperature $\left(<130^{\circ} \mathrm{C}\right)$ using LA and FAL as starting materials using similar zeolite-based catalysts. The reason for the lower yield can be attributed to the microporous structure of the Y-zeolite, in which the undesired 5-ethoxymethylfurfural (EMF) intermediate was formed and affected the rehydration step (Saravanamurugan and Riisager, 2012). Interestingly, H-USY zeolite has a superior BET surface area $\left(732 \mathrm{~m}^{2} \cdot \mathrm{g}^{-1}\right)$ and acid density $\left(1383 \mu \mathrm{mol} \cdot \mathrm{g}^{-1}\right)$, which exhibits better textural properties, to give a higher EL yield $(\sim 52 \%)$ at $160^{\circ} \mathrm{C}$ when compared to the weaker zeolite $\left(699 \mathrm{~m}^{2} \cdot \mathrm{g}^{-1}, 874 \mu \mathrm{mol} \cdot \mathrm{g}^{-1}\right.$, EL yield $\sim 40 \%$ ) (Saravanamurugan and Riisager, 2012, 2013; Li et al., 2016). Thus, the structural characteristics including the pore structure, surface area, and acid site density are significant toward obtaining higher EL yields over zeolite materials, which indicates that the microporous structure of zeolite catalysts may suppress the complete conversion of fructose into the key intermediates of the reaction.

When compared with fructose, the alcoholysis of glucose to prepare ALs has been demonstrated to be difficult. The experimental results confirm that the EL yield can be significantly decreased $(<13 \%)$ utilizing the same IL catalysts ([BMIm$\left.\mathrm{SO}_{3} \mathrm{H}\right]$ and $\left.\left[\mathrm{NEt}_{3} \mathrm{~B}-\mathrm{SO}_{3} \mathrm{H}\right]\right)$ when the substrate was changed from fructose to glucose under identical reaction conditions (Saravanamurugan et al., 2011). The low EL yield derived from glucose was attributed to the formation of ethyl-Dglucopyranoside (EDGP) in the presence of a Brønsted acid (Li et al., 2015c). Similar to the isomerization of glucose in fructose, EDGP isomerization to ethyl-D-fructofuranoside (EDFF) is catalyzed by a Lewis acid (Morales et al., 2014). Generally, the isomerization of EDGP into EDFF is difficult and is considered to be a rate-limiting step ( $\mathrm{Li}$ et al., 2015c). Therefore, the combination of both Brønsted and Lewis acid sites determines the successful conversion of glucose into EL (Zhao et al., 2015). Similar to the results obtained using ILs, several other catalysts have been investigated for the glucose alcoholysis reaction, which gave low yields of the target ALs. Interestingly, HPA acts as a catalyst over a shorter reaction time (120 $\mathrm{min})$ to achieve an equal yield of EL (Yang et al., 2012; Wang et al., 2013), which was attributed to the existence of both Lewis and Brønsted acid sites and the appropriate Brønsted to Lewis acid site ratio $(\mathrm{B} / \mathrm{L}>58)$ (Tao et al., 2015).

Zeolites possessing both moderate Brønsted and Lewis acidity have been explored by $\mathrm{Xu}$ et al. in the glucose ethanolysis reaction used toward the production of EL (Xu et al., 2013). An optimum EL yield of $40 \%$ was afforded at $180^{\circ} \mathrm{C}$ for over 30 min using USY zeolite starting from glucose. The moderate $\mathrm{B} / \mathrm{L}$ ratio $(\sim 3.7)$ of the USY zeolite was responsible for the good EL yield (West et al., 2010; Otomo et al., 2015). When further mineral acid $\left(\mathrm{H}_{2} \mathrm{SO}_{4}\right)$ was added to the USY zeolite, a higher EL yield of $51.4 \%$ was achieved over $120 \mathrm{~min}$ because of the increased $\mathrm{B} / \mathrm{L}$ ratio (Chang et al., 2015).

The amount of Brønsted acid in the catalyst plays an important role during the ethanolysis of glucose and fructose, giving different EL yields. This has been demonstrated during 
the ethanolysis of disaccharides, such as sucrose. For instance, in the presence of sulfonic acid functionalized ILs, the EL yield achieved after $24 \mathrm{~h}$ via ethanolysis of sucrose was $43 \%$ at $140^{\circ} \mathrm{C}$ (Saravanamurugan and Riisager, 2012). This result was attributed to the molecular components in sucrose, which includes one molecule of glucose and one molecule of fructose. The EL yield $(\sim 43 \%)$ obtained from sucrose was higher than that from glucose $(<13 \%)$ and lower than that from fructose $(>70 \%)$. This indicates that the glucose molecule in sucrose produces EDGP, which is the rate-limiting step and difficult to isomerize, while the fructose molecule is easily converted into EDFF, which may undergo subsequent reactions to form EMF and EL. In accordance with this conclusion, Chen et al. published a similar EL synthesis ( 45\%) using Brønsted acidic IL-based HPAs $[3.2 \mathrm{H}]_{3}\left(\mathrm{PW}_{12} \mathrm{O}_{40}\right)_{2}$ (IL POM) to convert sucrose into EL (Chen et al., 2014). Generally, in the presence of only a Brønsted acid, the fructose molecule in sucrose can be converted into EL without the transformation of glucose. For example, sulfonated SBA-15 has been applied as a catalyst and the yield of EL from sucrose decreased $(\sim 35 \%)$ when compared to that obtained from fructose (Saravanamurugan and Riisager, 2012). However, in the presence of both Brønsted and Lewis acid sites, two molecules of sucrose can simultaneously undergo ethanolysis to form EL ( $\mathrm{Li}$ et al., 2016). Different from sucrose, maltose contains two units of glucose, whose properties are similar to glucose. Therefore, the reactivity of maltose is similar to glucose, providing a better yield of EL when using the catalyst with an optimum ratio of Brønsted and Lewis acidity. The experimental exploration concluded by $\mathrm{Hu}$ et al. using maltose confirmed the above-mentioned hypothesis that a lower yield of EL (20\%) is obtained in the presence of Amberlyst-70 when compared with the EL yield (47\%) observed using H-USY (Hu et al., 2013; Saravanamurugan and Riisager, 2013).

Saravanamurugan et al. have studied polysaccharides constructed from fructose monomers, such as inulin, which provide excellent EL yields. The production of EL was found to conform to the same tendency as the Brønsted acidity of the catalyst used. For instance, high EL yields of up to $39.0,52.3$, and $67.0 \%$ have been obtained over H-USY zeolite, HPA, and IL functionalized polyoxometalate salts (IL-POM), respectively (Saravanamurugan and Riisager, 2013; Chen et al., 2014; Zhao et al., 2015). The Brønsted acidity followed the order of H-USY $<$ HPA $<$ IL-POM. Considering that cellulose is a glucose-based polysaccharide, the ethanolysis reaction was different under mild conditions for the production of EDGP and EL. Thus, the ethanolysis of cellulose conducted at temperatures $>170^{\circ} \mathrm{C}$ can offer an appreciable EL yield. Deng et al. reported an EL yield of $27 \%$ via the ethanolysis of cellulose using $\mathrm{HPA}\left(\mathrm{H}_{4} \mathrm{SiW}_{12} \mathrm{O}_{40}\right)$ at $205^{\circ} \mathrm{C}$ over $30 \mathrm{~min}$ (Deng et al., 2011). However, multiple undesired by-products which formed via polymerization may affect the overall EL selectivity, which was responsible for the low EL yield gained during cellulose ethanolysis using metal-doped HPA as a catalyst at an elevated temperature of $220^{\circ} \mathrm{C}$ (Zhao et al., 2015). Consequently, Amarasekara et al. introduced ethanol and water as the solvent medium for the ethanolysis of cellulose using an IL (1-(1-propylsulfonic)-3methylimidazolium chloride) as a catalyst. The existence of water favored the isomerization of glucose into fructose and avoided the formation of EDGP, resulting in a high yield of EL (38.5\%) (Amarasekara and Wiredu, 2014).

Le Van Mao et al. have developed two different approaches for the one-pot conversion of lignocellulosic biomass into EL catalyzed by an acid catalyst (Le Van Mao et al., 2011). The first method showed that biomass can be directly converted into EL in ethanol under acidic catalysis, while the second method proposed that biomass was first hydrolyzed to produce a complex mixture, which then undergoes the ethanolysis reaction. Both approaches used woody biomass or grass and were conducted in a high-pressure batch reactor in the presence of sulfuric acid at $190^{\circ} \mathrm{C}$ for $2 \mathrm{~h}$. The best yield was 16.6 wt.\%.

Chang et al. have investigated the direct conversion of wheat straw in one-pot to produce EL using $\mathrm{H}_{2} \mathrm{SO}_{4}$ as a catalyst (Chang et al., 2012). Under the optimal reaction conditions, a maximum EL yield of 17.9 wt.\% was observed from wheat straw. No significant increase in the EL yield was obtained upon increasing the sulfuric acid loading (Chang et al., 2015).

\section{CONCLUSIONS AND PERSPECTIVES}

This review summarizes the trends observed for the yields obtained for ALs from various starting materials including LA, FAL, CMF, monosaccharides, disaccharides, polysaccharides, and biomass residues using acid catalysts in the alcoholysis reaction. The esterification reaction used to produce EL mainly depends on the acid intensity, acid site density, and accessibility of the acid sites. The conversion of FAL depends on the intermediates obtained during the reaction. Glucose is difficult to react when compared to fructose, which avoids the isomerization step. An appropriate combination of Lewis and Brønsted acidity is needed for the transformation of glucose-based saccharides.

We can conclude that efficient catalytic procedures for the one-pot conversion of biomass directly into ALs and the separation and purification of ALs are urgently needed. Due to the complex structure of biomass and multifunctional active sites in the catalyst, green and sustainable process are highly desirable. As an alternative reaction approach, microwave irradiation has exhibited significant potential for reaction time reduction with fewer undesired products. The extensive exploration of microwave reactions for the transformation from lab scale to the industry scale to the synthesis of ALs needs to be studied further.

\section{AUTHOR CONTRIBUTIONS}

XL performed critical reviews and wrote the manuscript. CL and HW designed the structure of the manuscript and is responsible for the work. WY and QZ assisted XL in preparing and completing the review. All authors discussed the results, wrote, and commented on the manuscript. 


\section{FUNDING}

This work was financially supported by the National Natural Science Foundation of China (22065004), Basic Research Program of Guizhou Province [(2019)1009], the Guizhou Provincial Key Laboratory for Rare Animal and Economic Insects of the Mountainous Region

\section{REFERENCES}

Alloaoua, I., Goi, B. E., Obadia, M. M., Debuigne, A., and Detrembleur, C. (2014). (Co) Polymerization of vinyl levulinate by cobalt-mediated radical polymerization and functionalization by ketoxime click chemistry. Polym. Chem. 5, 2923-2929. doi: 10.1039/c3py01505j

Alsalme, A. M., Wiper, P. V., Khimyak, Y. Z., Kozhevnikova, E. F., and Kozhevnikov, I. V. (2010). Solid acid catalysts based on $\mathrm{H}_{3} \mathrm{PW}_{12} \mathrm{O}_{40}$ heteropoly acid: acid and catalytic properties at a gas-solid interface. J. Catal. 276, 181-189. doi: $10.1016 /$ j.jcat.2010.09.014

Amarasekara, A. S., and Wiredu, B. (2014). Acidic ionic liquid catalyzed one-pot conversion of cellulose to ethyl levulinate and levulinic acid in ethanol-water solvent system. BioEnergy Res. 7, 1237-1243. doi: 10.1007/s12155-014-9459-Z

Antunes, M. M., Lima, S., Fernandes, A., Pillinger, M., Ribeiro, M. F., and Valente, A. A. (2012). Aqueous-phase dehydration of xylose to furfural in the presence of MCM-22 and ITQ-2 solid acid catalysts. Appl. Catal. A 417-418, 243-252. doi: 10.1016/j.apcata.2011.12.046

Antunes, M. M., Lima, S., Neves, P., Magalhães, A. L., Fazio, E., Fernandes, A., et al. (2015). One-pot conversion of furfural to useful bio-products in the presence of a Sn,Al-containing zeolite beta catalyst prepared via post-synthesis routes. J. Catal. 329, 522-537. doi: 10.1016/j.jcat.2015.05.022

Antunes, M. M., Lima, S., Neves, P., Magalhães, A. L., Fazio, E., Neri, F., et al. (2016). Integrated reduction and acid-catalysed conversion of furfural in alcohol medium using $\mathrm{Zr}$, Al-containing ordered micro/mesoporous silicates. Appl. Catal. B 182, 485-503. doi: 10.1016/j.apcatb.2015.09.053

Badgujar, K. C., and Bhanage, B. M. (2015). Factors governing dissolution process of lignocellulosic biomass in ionic liquid: current status, overview and challenges. Bioresour. Technol. 178, 2-18. doi: 10.1016/j.biortech.2014.09.138

Badgujar, K. C., and Bhanage, B. M. (2018). Dedicated and Waste Feedstocks for Biorefinery: An Approach to Develop a Sustainable Society in Waste Biorefinery Potential and Perspective (India: Waste Biorefinery). ISBN: 978-0-444-63992-9.

Baronetti, G., Briand, L., Sedran, U., and Thomas, H. (1998). Heteropolyacidbased catalysis. Dawson acid for MTBE synthesis in gas phase. Appl. Catal. 172, 265-272. doi: 10.1016/S0926-860X(98)00134-3

Bloom, P. (2007). Levulinic acid ester derivatives as reactive plasticizers and coalescent solvents. Patent WO2007094922A2.

Breeden, S. W., Clark, J. H., Farmer, T. J., Macquarrie, D. J., Meimoun, J. S., Nonne, Y., et al. (2013). Microwave heating for rapid conversion of sugars and polysaccharides to 5-chloromethyl furfural. Green Chem. 15, 72-75. doi: 10.1039/C2GC36290B

Briand, L. E., Baronetti, G. T., and Thomas, H. J. (2003). The state of the art on Wells-Dawson heteropoly-compounds A review of their properties and applications. Appl. Catal., A 256, 37-50. doi: 10.1016/S0926-860X(03)00387-9

Chang, C., Xu, G., and Jiang, X. (2012). Production of ethyl levulinate by direct conversion of wheat straw in ethanol media. Bioresour. Technol. 121, 93-99. doi: 10.1016/j.biortech.2012.06.105

Chang, C., Xu, G., Zhu, W., Bai, J., and Fang, S. (2015). One-pot production of a liquid biofuel candidate-ethyl levulinate from glucose and furfural residues using a combination of extremely low sulfuric acid and zeolite USY. Fuel 140, 365-370. doi: 10.1016/j.fuel.2014.09.102

Chen, J., Zhao, G., and Chen, L. (2014). Efficient production of 5hydroxymethylfurfural and alkyl levulinate from biomass carbohydrate using ionic liquid-based polyoxometalate salts. RSC Adv. 4, 4194-4202. doi: 10.1039/C3RA45632C

Chermahini, A. N., and Nazeri, M. (2017). Esterification of the levulinic acid with $n$-butyl and isobutyl alcohols over aluminum-containing
[(2018)5102], the Scientific Research Platform For Qian $\mathrm{Ke} \mathrm{He}$ [(2017)5725], the Joint Science and Technology Funds of the Youth Growth S\&T Personnel Foundation of Guizhou Education Department [No. KY (2018)292], and the Discipline and Master's Site Construction Project of Guiyang University by Guiyang City Financial Support Guiyang University (SH-2020).
MCM-41. Fuel Process. Technol. 167, 442-450. doi: 10.1016/j.fuproc.2017. 07.034

Chia, M., Haider, M. A., Pollock, G., Kraus, G. A., Neurock, M., and Dumesic, J. A. (2013). Mechanistic insights into ring-opening and decarboxylation of 2pyrones in liquid water and tetrahydrofuran. J. Am. Chem. Soc. 135, 5699-5708. doi: $10.1021 /$ ja312075r

Christensen, E., Williams, A., Paul, S., Burton, S., and McCormick, R. L. (2011). Properties and performance of levulinate esters as diesel blend components. Energ Fuels 25, 5422-5428. doi: 10.1021/ef201229j

Cirujano, F. G., Corma, A., and Llabrés i Xamena, F. X. (2015). Conversion of levulinic acid into chemicals: Synthesis of biomass derived levulinate esters over Zr-containing MOFs. Chem. Eng. Sci. 124, 52-60. doi: 10.1016/j.ces.2014.09.047

Corma, A., Fornes, V., Pergher, S. B., Maesen, T. L. M., and Buglass, J. G. (1998). Delaminated zeolite precursors as selective acidic catalysts. Nature 396, 353-356. doi: 10.1038/24592

Cousinet, S. (2014). Biobased vinyl levulinate as styrene replacement for unsaturated polyester resin. Polym. Chem. 52, 3356-3364. doi: $10.1002 /$ pola.27397

Dave, C. D., and Pant, K. K. (2011). Glycerol conversion in the experimental study of catalytic hydrolysis of triglycerides for fatty acids production using $\mathrm{Ni}$ or $\mathrm{Pd}$ on $\mathrm{Al}_{2} \mathrm{O}_{3}$ or $\mathrm{SiO}_{2}$. Renew. Energ. 36, 3195-3202. doi: 10.1016/j.renene.2013.11.006

Démolis, A., Essayem, N., and Rataboul, F. (2014). Synthesis and applications of alkyl levulinates. ACS Sustain. Chem. Eng. 2, 1338-1352. doi: $10.1021 /$ sc500082n

Deng, W., Liu, M., Zhang, Q., and Wang, Y. (2011). Direct transformation of cellulose into methyl and ethyl glucosides in methanol and ethanol media catalyzed by heteropolyacids. Catal. Today 164, 461-466. doi: 10.1016/j.cattod.2010.10.055

Desidery, L., Yusubov, M. S., Zhuiykov, S., and Verpoort, F. (2018). Fully-sulfonated hydrated $\mathrm{UiO} 66$ as efficient catalyst for ethyl levulinate production by esterification. Catal. Commun. 117, 33-37. doi: 10.1016/j.catcom.2018.08.020

Dharne, S., and Bokade, V. V. (2011). Esterification of levulinic acid to n-butyl levulinate over heteropolyacid supported on acid-treated clay. J. Nat. Gas Chem. 20, 18-24. doi: 10.1016/S1003-9953(10)60147-8

Dhyani, V., and Bhaskar, T. (2018). A comprehensive review on the pyrolysis of lignocellulosic biomass. Renew. Energy 129, 695-716. doi: 10.1016/j.renene.2017.04.035

Dusselier, M., Van Wouwe, P., and Dewaele, A. (2015). Shape-selective zeolite catalysis for bioplastics production. Science 349, 78-80. doi: 10.1126/science.aaa7169

Enumula, S. S., Gurram, V. R. B., Chada, R. R., Burri, D. R., and Kamaraju, S. R. R. (2017). Clean synthesis of alkyl levulinates from levulinic acid over one pot Synthesized $\mathrm{WO}_{3}$-SBA-16 catalyst. J. Mol. Catal. A Chem. 426, 30-38. doi: 10.1016/j.molcata.2016.10.032

Fernandes, D. R., Rocha, A. S., Mai, E. F., Mota, C. J. A., and Teixeira Da Silva, V. (2012). Levulinic acid esterification with ethanol to ethyl levulinate production over solid acid catalysts. Appl. Catal. A 425-426, 199-204. doi: 10.1016/j.apcata.2012.03.020

Fiorentino, G., Ripa, M., Mellino, S., Fahd, S., and Ulgiati, S. (2014). Life cycle assessment of Brassica carinata biomass conversion to bioenergy and platform chemicals. J. Cleaner Prod. 66, 174-187. doi: 10.1016/j.jclepro.2013.11.043

González Maldonado, G. M., Assary, R. S., Dumesic, J. A., and Curtiss, L. A. (2012). Acid-catalyzed conversion of furfuryl alcohol to ethyl levulinate in liquid ethanol. Energ. Environ. Sci. 5, 8990-8997. doi: 10.1039/c2ee22486k 
Guo, H. X., Hirrosaki, Y., Qi, X. H., and Smith, R. L. (2020). Synthesis of ethyl levulinate over amino-sulfonated functional carbon materials. Renew Energ. 157, 951-958. doi: 10.1016/j.renene.2020.05.103

Gupta, P., and Paul, S. (2014). Solid acids: green alternatives for acid catalysis. Catal. Today 236, 153-170. doi: 10.1016/j.cattod.2014.04.010

Gupta, S., Arora, R., Sinha, N., Alam, M. I., and Haider, M. A. (2016). Mechanistic insights into the ring-opening of biomass derived lactones. RSC $A d v$. 6, 12932-12942. doi: 10.1039/C5RA22832H

Hengne, A. M., Kamble, S. B., and Rode, C. V. (2013). Single pot conversion of furfuryl alcohol to levulinic esters and $\gamma$-valerolactone in the presence of sulfonic acid functionalized ILs and metal catalysts. Green Chem. 15, 2540-2547. doi: 10.1039/c3gc41098f

Hu, L., Lin, L., Wu, Z., Zhou, S. Y., and Liu, S. J. (2015). Chemocatalytic hydrolysis of cellulose into glucose over solid acid catalysts. Appl. Catal. B Environ. 174-175, 225-243. doi: 10.1016/j.apcatb.2015.03.003

Hu, X., Wu, L., Wang, Y., Song, Y., Mourant, D., Gunawan, R., et al. (2013). Acidcatalyzed conversion of mono- and poly-sugars into platform chemicals: effects of molecular structure of sugar substrate. Bioresour. Technol. 133, 469-474. doi: 10.1016/j.biortech.2013.01.080

Huang, Y., Yang, T., Zhou, M., and Fu, Y. (2016). Microwave-assisted alcoholysis of furfural alcohol into alkyl levulinates catalyzed by metal salts. Green Chem. 18, 1516-1523. doi: 10.1039/C5GC01581B

Janik, M. J., Davis, R. J., and Neurock, M. (2005). Anhydrous and water-assisted proton mobility in phosphotungstic acid. J. Am. Chem. Soc. 127, 5238-5245. doi: $10.1021 / j a 042742$ o

Khusnutdinov, R. I., Baiguzina, A. R., Smirnov, A. A., Mukminov, R. R., and Dzhemilev, U. M. (2007). Furfuryl alcohol in synthesis of levulinic acid esters and difurylmethane with $\mathrm{Fe}$ and $\mathrm{Rh}$ complexes. Russ. J. Appl. Chem. 80, 1687-1690. doi: 10.1134/S1070427207100163

Kokare, M. B., Rajani, V., and Mathpati, C. S. (2018). Response surface optimization, kinetic study and process design of n-butyl levulinate synthesis. Chem. Eng. Res. Des. 137, 577-588.

Kuwahara, Y., Fujitani, T., and Yamashita, H. (2013). Esterification of levulinic acid with ethanol over sulfated mesoporous zirconosilicates: influences of the preparation conditions on the structural properties and catalytic performances. Catal. Today 237, 18-28. doi: 10.1016/j.cattod.2013.11.008

Kuwahara, Y., Kaburagi, W., Nemoto, K., and Fujitani, T. (2014). Esterefication of levulinic acid with ethanol over sulfated Si-doped $\mathrm{ZrO}_{2}$ solid acid catalyst: study of the structure-activity relationships. Appl. Catal. A 476, 186-196. doi: 10.1016/j.apcata.2014.02.032

Lange, J., Van De Graaf, W. D., and Haan, R. J. (2009). Conversion of furfuryl alcohol into ethyl levulinate using solid acid catalysts. ChemSusChem 2, 437-441. doi: 10.1002/cssc.200800216

Le Van Mao, R., Zhao, Q., Dima, G., and Petraccone, D. (2011). New process for the acid-catalyzed conversion of cellulosic biomass $\left(\mathrm{AC}_{3} \mathrm{~B}\right)$ into alkyl levulinates and other esters using a unique one-pot system of reaction and product extraction. Catal. Lett. 141, 271-276. doi: 10.1007/s10562-010-0493-y

Li, H., Bhadury, P. S., Riisager, A., and Yang, S. (2014). One-pot transformation of polysaccharides via multi-catalytic processes. Catal. Sci. Technol. 4, 4138-4168. doi: 10.1039/C4CY00711E

Li, H., Fang, Z., and Yang, S. (2016). Direct conversion of sugars and ethyl levulinate into $\gamma$-valerolactone with superparamagnetic acid-base bifunctional $\mathrm{ZrFeO}_{\mathrm{x}}$ nanocatalysts. ACS Sustainable Chem. Eng. 4, 236-246. doi: 10.1021/acssuschemeng.5b01480

Li, H., Saravanamurugan, S., Yang, S., and Riisager, A. (2015a). Direct transformation of carbohydrates to the biofuel 5-ethoxymethylfurfural by solid acid catalysts. Green Chem. 18, 726-734. doi: 10.1039/C5GC01043H

Li, J., Li, J., Zhang, D., and Liu, C. (2015b). Theoretical Elucidation of Glucose Dehydration to 5-Hydroxymethylfurfural Catalyzed by a $\mathrm{SO}_{3} \mathrm{H}$-Functionalized Ionic Liquid. J. Phys. Chem. B 119, 13398-13406. doi: 10.1021/acs.jpcb.5b07773

Li, J., Li, J., Zhang, D., and Liu, C. (2015c). Theoretical explanation for how $\mathrm{SO}_{3} \mathrm{H}-$ functionalized ionic liquids promote the conversion of cellulose to glucose, ChemPhysChem 16, 3044-3048. doi: 10.1002/cphc.201500424

Li, Z., Liu, Y., Kwapinski, W., and Leahy, J. J. (2014). $\mathrm{ZrO}_{2}$-modified $\mathrm{TiO}_{2}$ nanorod composite: hydrothermal synthesis, characterization and application in esterification of organic acid. Mater. Chem. Phys. 145, 82-89. doi: 10.1016/j.matchemphys.2014.01.037
Li, Z., Wnetrzak, R., Kwapinski, W., and Leahy, J. J. (2012). Synthesis and characterization of sulfated $\mathrm{TiO}_{2}$ nanorods and $\mathrm{ZrO}_{2} / \mathrm{TiO}_{2}$ nanocomposites for the esterification of biobased organic acid. ACS Appl. Mater. Interfaces 4, 4499-4505. doi: 10.1021/am300510u

Lima, S., Antunes, M. M., Fernandes, A., Pillinger, M., Ribeiro, M. F., and Valente, A. A. (2010a). Catalytic cyclodehydration of xylose to furfural in the presence of zeolite H-Beta and a micro/mesoporous Beta/TUD-1 composite material. Appl. Catal. A 388, 141-148. doi: 10.1016/j.apcata.2010. 08.040

Lima, S., Antunes, M. M., Fernandes, A., Pillinger, M., Ribeiro, M. F., and Valente, A. A. (2010b). Acid-Catalysed Conversion of Saccharides into Furanic Aldehydes in the Presence of Three-Dimensional Mesoporous Al-TUD-1. Molecules 15, 3863-3877. doi: 10.3390/molecules15063863

Liu, G., Wu, J., Zhang, I. Y., Chen, Z., Li, Y., and Xu, X. (2011). Theoretical studies on thermochemistry for conversion of 5-chloromethylfurfural into valuable. J. Phys. Chem. A 115, 13628-13641. doi: 10.1021/jp207641g

Liu, R., Chen, J., Huang, X., Chen, L., Ma, L., and Li, X. (2013). Conversion of fructose into 5-hydroxymethylfurfural and alkyl levulinates catalyzed by sulfonic acid-functionalized carbon materials. Green Chem. 15, 2895-2903. doi: $10.1039 / \mathrm{c} 3 g c 41139 \mathrm{~g}$

Liu, X., Zhou, J., Guo, X., Liu, M., Ma, X., Song, C., et al. (2008). SO ${ }_{3}$ Hfunctionalized ionic liquids for selective alkylation of $p$-cresol with tert-butanol. Ind. Eng. Chem. 47, 5298-5303. doi: 10.1021/ie070647t

Liu, X. F., Li, H., Zhang, H.eng., Pan, H., Huang, S., Yang, K. L., et al. (2016). Efficient conversion of furfuryl alcohol to ethyl levulinate with sulfonic acid-functionalized MIL-101(Cr). RSC Adv. 6, 90232-90238. doi: 10.1039/C6RA19116A

Loerbroks, C., van Rijn, J., Ruby, M. P., Tong, Q., Schuth, F., and Thiel, W. (2014). Reactivity of metal catalysts in glucose-fructose conversion. Chemistry 20, 12298-12309. doi: 10.1002/chem.201402437

Lomba, L., Giner, B., Bandres, I., Lafuente, C., and Pino, M. R. (2011). Physicochemical properties of green solvents derived from biomass. Green Chem. 13, 2062-2070. doi: 10.1039/c0gc00853b

López, X., Carbó, J. J., Bo, C., and Poblet, J. M. (2012). Structure, properties and reactivity of polyoxometalates: a theoretical perspective. Chem. Soc. Rev. 41, 7537-7571. doi: 10.1039/c2cs35168d

Luan, Q. J., Liu, L. J., Gong, S. W., Lu, J., Wang, X., and Lv, D. M. (2018). Clean efficient conversion of renewable levulinic acid to levulinate esters catalyzed by an organic-salt of $\mathrm{H}_{4} \mathrm{SiW}_{12} \mathrm{O}_{40}$. Process Saf. Environ. Prot. 117, 341-349. doi: 10.1016/j.psep.2018.05.015

Lucas, N., Gurrala, L., and Athawale, A. (2019). Heteropolyacids supported on mesoporous AlSBA-15 as efficient catalysts for esterification of levulinic acid. J. Porous Mater. 26, 1335-1343. doi: 10.1007/s10934-019-00734-w

Macht, J., Janik, M. J., Neurock, M., and Iglesia, E. (2007). Catalytic consequences of composition in polyoxometalate clusters with Keggin structure. Angew. Chem. Int. Ed. 46, 7864-7868. doi: 10.1002/anie.200701292

Macht, J., Janik, M. J., Neurock, M., and Iglesia, E. (2008). Mechanistic consequences of composition in acid catalysis by polyoxometalate Keggin clusters. J. Am. Chem. Soc. 10369-10379. doi: 10.1021/ja803114r

Maggi, R., Shiju, N. R., Santacroce, V., Maestri, G., Bigi, F., and Rothenberg, G. (2016). Silicasupported sulfonic acids as recyclable catalyst for esterification of levulinic acid with stoichiometric amounts of alcohols. Beilstein J. Org. Chem. 12, 2173-2180. doi: 10.3762/bjoc.12.207

Manikandan, K., and Cheralathan, K. K. (2017). Heteropoly acid supported on silicalite-1 possesing intracrystalline nanovoids prepared using biomass-an efficient and recyclable catalyst for esterification of levulinic acid. Appl. Catal. A Gen. 547, 237-247. doi: 10.1016/j.apcata.2017.09.007

Marrocchi, A., and Vaccaro, L. (2017). Efficient catalytic upgrading of levulinic acid into alkyl levulinates by resin-supported acids and flow reactors. Catalysts 7 , 235-248. doi: 10.3390/catal7080235

Mascal, M., and Nikitin, E. B. (2010a). Co-processing of carbohydrates and lipids in oil crops to produce a hybrid biodiesel. Energy Fuels 24, 2170-2171. doi: $10.1021 /$ ef9013373

Mascal, M., and Nikitin, E. B. (2010b). High-yield conversion of plant biomass into the key value-added feedstocks 5-(hydroxymethyl)furfural, levulinic acid, and levulinic esters via5-(chloromethyl)furfural. Green Chem. 12, 370-373. doi: 10.1039/B918922J 
Melero, J. A., Morales, G., Iglesias, J., Paniagua, M., Hernández, B., and Penedo, S. (2013). Efficient conversion of levulinic acid into alkyl levulinates catalyzed by sulfonic mesostructured silicas. Appl. Catal. A 466, 116-122. doi: 10.1016/j.apcata.2013.06.035

Mondal, T., Pant, K. K., and Dalai, A. K. (2015). Catalytic oxidative steam reforming of bio-ethanol for hydrogen production over $\mathrm{Rh}$ promoted $\mathrm{Ni} / \mathrm{CeO}_{2}-\mathrm{ZrO}_{2}$ catalyst. Int. J. Hydro. Energy 40, 2529-2544. doi: 10.1016/j.ijhydene.2014.12.070

Morales, G., Osatiashtiani, A., Herna, B., Iglesias, J., Melero, J. A., Paniagua, M., et al. (2014). Conformal sulfated zirconia monolayer catalystsfor the one-pot synthesis of ethyl levulinate fromglucose. Chem. Commun. 50, 11742-11745. doi: 10.1039/C4CC04594G

Mukherjee, A., Dumont, M. J., and Raghavan, V. (2015). Review: sustainable production of hydroxymethylfurfural and levulinic acid: challenges and opportunities. Biomass Bioenerg. 72, 143-183. doi: 10.1016/j.biombioe.2014.11.007

Mullen, B. D., Badarinarayana, V., Hall, E. S., Tjossas, M. J., and Leibig, C. M. (2013). Stabilized levulinic ester ketals. Patent WO2013055781A1.

Nandiwale, K. Y., and Bokade, V. V. (2015). Esterification of renewable levulinic acid to $n$-butyl levulinate over modified H-ZSM-5. Chem. Eng. Technol. 38, 246-252. doi: 10.1002/ceat.201400326

Nandiwale, K. Y., Niphadkar, P. S., Deshpande, S. S., and Bokade, V. V. (2014). Esterification of renewable levulinic acid to ethyl levulinate biodiesel catalyzed by highly active and reusable desilicated H-ZSM-5. J. Chem. Technol. Biotechnol. 89, 1507-1515. doi: 10.1002/jctb.4228

Nandiwale, K. Y., Pande, A. M., and Bokade, V. V. (2015). One step synthesis of ethyl levulinate biofuel by ethanolysis of renewable furfuryl alcohol over hierarchical zeolite catalyst. RSC Adv. 5, 79224-79231. doi: 10.1039/C5RA13520F

Nandiwale, K. Y., Sonar, S. K., Niphadkar, P. S., Joshi, P. N., Deshpande, S. S., Patil, V. S., et al. (2013). Appl. Catal. A 460-461, 90-98. doi: 10.1016/j.apcata.2013.04.024

Narkhede, N., Singh, S., and Patel, A. (2015). Recent progress on supported polyoxometalates for biodiesel synthesis via esterification and transesterification. Green Chem. 17, 89-107. doi: 10.1039/C4GC01743A

Neves, P., Lima, S., Pillinger, M., Rocha, S. M., Rocha, J., and Valente, A. A. (2013). Conversion of furfuryl alcohol to ethyl levulinate using porous aluminosilicate acid catalysts. Catal. Today 218-219, 76-84. doi: 10.1016/j.cattod.2013.04.035

Ogino, I., Eilertsen, E. A., Hwang, S. J., Rea, T., Xie, D., Ouyang, X., et al. (2013). Heteroatom-tolerant delamination of layered zeolite precursor materials. Chem. Mater. 25, 1502-1509. doi: 10.1021/cm3032785

Oliveira, B. L., and Teixeira Da Silva, V. (2014). Synthesis of ethyl levulinate, a perspective biocomponent of motor fuels. Sci. Net. Catal. Today 234, 257-263. doi: 10.1016/j.cattod.2013.11.028

Otomo, R., Yokoi, T., and Tatsumi, T. (2015). OSDA-free zeolite beta with high aluminum content efficiently catalyzes a tandem reaction for conversion of glucose to 5-hydroxymethylfurfural. ChemCatChem 7, 4180-4187. doi: $10.1002 /$ cctc.201500837

Pasquale, G., Vázquez, P., Romanelli, G., and Baronetti, G. (2012). Catalytic upgrading of levulinic acid to ethyl levulinate using reusable silica-included Wells-Dawson heteropolyacid as catalyst. Catal. Commun. 18, 115-120. doi: 10.1016/j.catcom.2011.12.004

Patil, C. R., Niphadkar, P. S., Bokade, V. V., and Joshi, P. N. (2014). Esterification of levulinic acid to ethyl levulinate over bimodal micromesoporous H/BEA zeolite derivatives. Catal. Commun. 43, 188-191. doi: $10.1016 / j . c a t c o m .2013 .10 .006$

Peng, L., Gao, X., and Chen, K. (2015). Catalytic upgrading of renewable furfuryl alcohol to alkyl levulinates using $\mathrm{AlCl}_{3}$ as a facile, efficient, and reusable catalyst. Fuel 160, 123-131. doi: 10.1016/j.fuel.2015.07.086

Peng, L., Lin, L., Zhang, J., Shi, J., and Liu, S. (2011). Solid acid catalyzed glucose conversion to ethyl levulinate. Appl. Catal. A 397, 259-265. doi: 10.1016/j.apcata.2011.03.008

Pidko, E. A., Degirmenci, V., Van Santen, R. A., and Hensen, E. J. M. (2010). Glucose activation by transient $\mathrm{Cr}^{2+}$ dimers. Angew. Chem. Int. Ed. 49, 2530-2534. doi: 10.1002/anie.201000250

Pileidis, F. D., and Titirici, M. M. (2016). Levulinic acid biorefineries: new challenges for efficient utilization of biomass. ChemSusChem 9, 562-582. doi: $10.1002 /$ cssc. 201501405
Rackemann, D. W., Doherty, W. O. S. (2011). The conversion of lignocellulosics to levulinic acid. Biofuels BioprodBioref 5, 198-214. doi: 10.1002/bbb.267

Ramli, N. A. S., Amin, N. A. S., and Sivasubramaniam, D. (2017a). Esterification of levulinic acid using $\mathrm{ZrO}$-supported phosphotungstic acid catalyst for ethyl levulinate production. Bioenerg. Res. 10, 1-12. doi: 10.1007/s12155-017-9872-1

Ramli, N. A. S., Hisham, N. I., and Amin, A. S. (2018). Esterification of levulinic acid to levulinate esters in the presence of sulfated silica catalyst. Sains Malays. 47,1131-1138. doi: 10.17576/jsm-2018-4706-08

Ramli, N. A. S., Zaharuddin, N. H., and Amin, N. A. S. (2017b). Esterification of renewable levuininc acid to levulinate ester using Amberlyst 15 as a solid acid catalyst. J. Teknologi. 79, 137-142. doi: 10.11113/jt.v79.8095

Rao, Y., Trudeau, M., and Antonelli, D. (2006). Sulfated and phosphated mesoporous $\mathrm{Nb}$ oxide in the benzylation of anisole and toluene by benzyl alcohol. J. Am. Chem. Soc. 128, 13996-13997. doi: 10.1021/ja0647147

Russo, P. A., Antunes, M. M., Neves, P., Wiper, P. V., Fazio, E., Neri, F., et al. (2014a). Mesoporous carbon-silica solid acid catalysts for producing useful bio-products within the sugar-platform of biorefineries. Green Chem. 16, 4292-4305. doi: 10.1039/C4GC01037J

Russo, P. A., Antunes, M. M., Neves, P., Wiper, P. V., Fazio, E., Neri, F., et al. (2014b). Solid acids with $\mathrm{SO}_{3} \mathrm{H}$ groups and tunable surface properties: versatile catalysts for biomass conversion. J. Mater. Chem. A 2, 11813-11824. doi: 10.1039/C4TA02320J

Ryder, J. A., Chakraborty, A. K., and Bell, A. T. (2000). Density functional theory study of proton mobility in zeolites: proton migration and hydrogen exchange in ZSM-5. J. Phys. Chem. B 104, 6998-7011. doi: 10.1021/jp9943427

Saravanamurugan, S., and Riisager, A. (2012). Solid acid catalysed formation of ethyl levulinate and ethyl glucopyranoside from mono- and disaccharides. Catal. Commun. 17, 71-75. doi: 10.1016/j.catcom.2011.10.001

Saravanamurugan, S., and Riisager, A. (2013). Zeolite catalyzed transformation of carbohydrates to alkyl levulinates. ChemCatChem 5, 1754-1757. doi: $10.1002 /$ cctc. 201300006

Saravanamurugan, S., Van Buu, O. N., and Riisager, A. (2011). Conversion of mono- and disaccharides to ethyl levulinate and ethyl pyranoside with sulfonic acid-functionalized ionic liquids. ChemSusChem 4, 723-726. doi: $10.1002 /$ cssc. 201100137

Song, D., An, S., Lu, B., Guo, Y., and Leng, J. (2015). Arylsulfonic acid functionalized hollow mesoporous carbon spheres for efficient conversion of levulinic acid or furfuryl alcohol to ethyl levulinate. Appl. Catal., B 179, 445-457. doi: 10.1016/j.apcatb.2015.05.047

Su, F., Ma, L., Song, D., Zhang, X., and Guo, Y. (2013a). Design of a highly ordered mesoporous $\mathrm{H}_{3} \mathrm{PW}_{12} \mathrm{O}_{40} / \mathrm{ZrO}^{2-} \mathrm{Si}(\mathrm{Ph}) \mathrm{Si}$ hybrid catalyst for methyl levulinate synthesis. Green Chem. 15, 885-890. doi: 10.1039/c3g c36912a

Su, F., Wu, Q., Song, D., Zhang, X., Wang, M., and Guo, Y. (2013b). Pore morphology-controlled preparation of $\mathrm{ZrO} 2$-based hybrid catalysts functionalized by both organosilica moieties and Keggin-type heteropoly acid for the synthesis of levulinate esters. J. Mater. Chem. A 1, 13209-13221. doi: $10.1039 / \mathrm{c} 3 \mathrm{ta1} 2412 \mathrm{f}$

Sun, Y., and Cheng, J. (2002). Hydrolysis of lignocellulosic materials for ethanol production: a review. Bioresour. Technol. 83, 1-11. doi: 10.1016/S0960-8524(01)00212-7

Tadele, K., Verma, S., Gonzalez, M. A., and Varma, R. S. (2017). A sustainable approach to empower the bio-based future: upgrading of biomass via process intensification. Green Chem. 19, 1624-1627. doi: 10.1039/C6GC03568J

Tao, M., Xue, L., Sun, Z., Wang, S., Wang, X., and Shi, J. (2015). Tailoring the synergistic bronsted-lewis acidic effects in heteropolyacid catalysts: applied in esterification and transesterification reactions. Sci. Rep. 5:13764. doi: $10.1038 /$ srep 13764

Tejero, M. A., Ramírez, E., Fité, C., Tejero, J., and Cunill, F. (2016). Esterification of levulinic acid with butanol over ion exchange resins. Appl. Catal. A Gen. 517, 56-66. doi: 10.1016/j.apcata.2016.02.032

Trombettoni, V., Bianchi, L., Zupanic, A., Porciello, A., Cuomo, M., Piermatti, O., et al. (2018). Response surface optimization, kinetic study and process design of $n$-butyl levulinate synthesis. Chem. Eng. Res. Des. 137, 577-588. doi: 10.1016/j.cherd.2018.07.036

Tsucha, J., and Yoshida, K. (1994). Skin cosmetics containing levulinates, glycyrrizates, and resorcinol or isopropylmethylphenol. Japanese patent 05320023 to Kanebo. 
Vilanculo, C. B., Leles, L. C. A., and Silva, M. J. (2018). $\mathrm{H}_{4} \mathrm{SiW}_{12} \mathrm{O}_{40^{-}}$ catalyzed levulinic acid esterification at room temperature for production of fuel bioadditives. Waste Biomass Valori. 11, 1895-1904. doi: 10.1007/s12649-018-00549-x

Wagh, K. V., Badgujar, K. C., Patil, N. M., and Bhanage, B. M. (2016). Recent trends of ionic liquids for the synthesis of 5-hydroxymethylfurfural. Curr. Org. Chem. 20, 736-751. doi: 10.2174/1385272819666150716173605

Wang, G., Zhang, Z., and Song, L. (2014). Efficient and selective alcoholysis of furfuryl alcohol to alkyl levulinates catalyzed by double $\mathrm{SO}_{3} \mathrm{H}$-functionalized ionic liquids. Green Chem. 16, 1436-1443. doi: 10.1039/C3GC41693C

Wang, H., Deng, T., Wang, Y., Qi, Y., Hou, X., and Zhu, Y. (2013). Efficient catalytic system for the conversion of fructose into 5-ethoxymethylfurfural. Bioresour. Technol. 136, 394-400. doi: 10.1016/j.biortech.2013.02.110

West, R. M., Holm, M. S., Saravanamurugan, S., Xiong, J., Beversdorf, Z., Taarning, E., et al. (2010). Zeolite H-USY for the production of lactic acid and methyl lactate from C3-sugars. J. Catal. 269, 122-130. doi: 10.1016/j.jcat.2009.10.023

Windom, B. C., Lovestead, T. M., Mascal, M., Nikitin, E. B., and Bruno, T. J. (2011). Advanced distillation curve analysis on ethyl levulinate as a diesel fuel oxygenate and a hybrid biodiesel fuel. Energ Fuels 25, 1878-1890. doi: 10.1021/ef200239x

Wu, M., Zhang, X., Su, X., Li, X., Zheng, X., Guan, X., et al. (2016b). 3D graphene aerogel anchored tungstophosphoric acid catalysts: characterization and catalytic performance for levulinicacid esterification with ethanol. Catal. Commun. 85, 66-69. doi: 10.1016/j.catcom.2016.07.023

Wu, M., Zhao, Q-Q., Li, J., Su, X-L., Wu, H-Y., Guan, X-X., et al. (2016a). Tungstophosphoric acid-based mesoporous materials anchored to MCM-41: characterization and catalytic performance in esterification of levulinic acid with ethanol. J. Porous. Mater. 23,1329-1338. doi: 10.1007/s10934-016-0192-1

Wu, M., Zhao, Q. Q., Li, J., Wu, H. Y., Zheng, X. C., Guan, X. X., et al. (2016c). Esterification of levulinic acid into hexyl levulinate over dodecatungstophosphoric acid anchored to Al-MCM-41. J. Exp. Nanosci. 11, 1331-1347. doi: 10.1080/17458080.2016.1214985

Xu, G., Chang, C., Zhu, W., Li, B., and Du, F. (2013). A comparative study on direct production of ethyl levulinate from glucose in ethanol media catalysed by different acid catalysts. Chem. Pap. 67, 1355-1363. doi: 10.2478/s11696-013-0410-0

Yadav, G. D., and Nair, J. J. (1999). Sulfated zirconia and its modified versions as promising catalysts for industrial processes. Micro. Meso. Mater. 33, 1-48. doi: 10.1016/S1387-1811(99)00147-X

Yadav, G. D., and Yadav, A. R. (2014). Synthesis of ethyl levulinate as fuel additives using heterogeneous solid superacidic catalysts: efficacy and kinetic modeling. Chem. Eng. J. 243, 556-563. doi: 10.1016/j.cej.2014. 01.013

Yamaguchi, A., and Shirai, M. (2016). Catalytic production of sugar alcohols from lignocellulosic biomass. Catal. Today 265, 199-202. doi: 10.1016/j.cattod.2015.08.026
Yan, K., Wu, G., Wen, J., and Chen, A. (2013). One-step synthesis of mesoporous $\mathrm{H}_{4} \mathrm{SiW}_{12} \mathrm{O}_{40}$ catalysts for the production of methyl and ethyl levulinate biodiesel. Catal. Commun. 34, 58-63. doi: 10.1016/j.catcom.2013.01.010

Yang, F., and Tang, J. (2019). Catalytic upgrading of renewable levulinic acid to levulinate esters using perchloric acid decorated nanoporous silica gels. Chem. Select 1403-1409. doi: 10.1002/slct.201803608

Yang, Y., Abu-Omar, M. M., and Hu, C. (2012). Heteropolyacid catalyzed conversion of fructose, sucrose, and inulin to 5-ethoxymethylfurfural, a liquid biofuel candidate. Appl. Energ. 99, 80-84. doi: 10.1016/j.apenergy.2012.04.049

Yontz, D. J. (2011). Fabricating fragrant formulations from essential oils and solvents as olfactory flavorants for food, fragrances for candles, cosmetics, soaps or other uses. U.S. Patent US20110274643A1.

Zhang, J., and Chen, J. (2016). Modified solid acids derived from biomass based cellulose for one-step conversion of carbohydrates into ethyl levulinate. J. Energy Chem. 25, 747-753. doi: 10.1016/j.jechem.2016.06.005

Zhang, Z., Dong, K., and Zhao, Z. (2011). Efficient conversion of furfuryl alcohol into alkyl levulinates catalyzed by an organic-inorganic hybrid solid acid catalyst. ChemSusChem 4, 112-118. doi: 10.1002/cssc.201000231

Zhao, S., Xu, G., Chang, C., Fang, S., Liu, Z., and Du, F. (2015). Direct conversion of carbohydrates into ethyl levulinate with potassium phosphotungstate as an efficient catalyst. Catalysts 5, 1897-1910. doi: 10.3390/catal5041897

Zheng, X. C., Guan, X., Li, N., Zhang, X. L., and Wu, M. (2017). Synthesis of biofuel via levulinic acid esterification over porous solid acid consisting of tungstophosphoricacid and reduced graphene oxide. Res. Chem. Intermed. 43, 6651-6664. doi: 10.1007/s11164-017-3012-6

Zhou, X., Li, Z. X., Zhang, C., Gao, X. P., Dai, Y. Z., and Wang, G. Y. (2016). Efficient conversion of renewable levulinic acid to n-butyl levulinate catalyzed by ammonium and silver co-doped phosphotungstic acid. J. Mol. Catal. A Chem. 417, 71-75. doi: 10.1016/j.molcata.2016.03.006

Zhu, S., Chen, C., Xue, Y., Wu, J., Wang, J., and Fan, W. (2014). Graphene oxide: an efficient acid catalyst for alcoholysis and esterification reactions. ChemCatChem 6, 3080-3083. doi: 10.1002/cctc.201402574

Zhu, S., Wang, J., and Fan, W. (2015). Graphene-based catalysis for biomass conversion. Catal. Sci. Technol. 5, 3845-3858. doi: 10.1039/C5CY00339C

Conflict of Interest: The authors declare that the research was conducted in the absence of any commercial or financial relationships that could be construed as a potential conflict of interest.

Copyright (c) $2020 \mathrm{Liu}$, Yang, Zhang, Li and Wu. This is an open-access article distributed under the terms of the Creative Commons Attribution License (CC BY). The use, distribution or reproduction in other forums is permitted, provided the original author(s) and the copyright owner(s) are credited and that the original publication in this journal is cited, in accordance with accepted academic practice. No use, distribution or reproduction is permitted which does not comply with these terms. 